\title{
A ocupação do espaço público para a resolução de conflitos: construindo cidades criativas
}

The occupation of public space for solution of conflicts: building creative cities

La ocupación del espacio público para la resolución de conflictos: construyendo ciudades creativas

Elisangela Machado Mortari

- Doutora e mestre em Comunicação e Cultura pela Universidade Federal do Rio de Janeiro (UFRJ)

- Mestre em Comunicação e Cultura pela Universidade Federal do Rio de Janeiro (UFRJ)

- Graduação em Comunicação Social - Relações Públicas pela Universidade Federal de Santa Maria (UFSM)

- Professora associada do Departamento de Ciências da Comunicação da UFSM

- Coordenadora da Agência Experimental de Relações Públicas da UFSM

- Líder do grupo de estudos "Comunicação e gerenciamento de crises"

- E-mail: elimortari@gmail.com 


\section{Resumo}

A proposta deste artigo é provocar um novo percurso que conduza as organizações para a superação do estado de crise, levandoas ao entendimento do conflito como inerente a todos os ambientes sociais, culturais e econômicos. 0 primeiro passo está no conhecimento da ação organizacional frente à ocupação do espaço público como lugar empreendedor de indústrias criativas e consequentemente formador de cidades criativas. A sinergia das organizações na ocupação do lugar público permitirá que os conflitos sejam conduzidos ao status de produção de afetos, gerando bem-estar social, cultural e econômico para os cidadãos.

\section{PALAVRAS-CHAVE: CONFLITOS • ESPAÇO PÚBLICO • CIDADES CRIATIVAS.}

\section{Abstract}

The purpose of this article is to create a new path that leads organizations to overcome the state of crisis leading them to understand the conflict as being inherent in all social, cultural and economic environments. The first step is in the knowledge of the organizational action in view of the occupation of the public space as an enterprising site of creative industries and consequently a developer of creative cities. The synergy of organizations in the occupation of public space will allow conflicts to be conducted to the affections production status, generating social, cultural and economic well-being for the citizens.

\section{KEYWORDS: CONFLICT・PUBLIC SPACE・CREATIVE CITIES.}

\section{Resumen}

La propuesta de este artículo es la de provocar una nueva ruta que lleve a las organizaciones a superar el estado de crisis, llevándolas a la comprensión del conflicto como inherente a todos los ámbitos sociales, culturales y económicos. El primer paso es el del conocimiento de la acción de la organización delante de la ocupación del espacio público como un espacio de iniciativa empresarial para industrias creativas y en consecuencia de formación de ciudades creativas. La sinergia de las organizaciones en la ocupación del lugar público permitirá que los conflictos sean conducidos al status de producción de afectos, generando bienestar social, cultural y económico para los ciudadanos.

\section{PALABRAS CLAVES: CONFLICTOS • ESPACIO PÚBLICO • CIUDADES CREATIVAS.}


s práticas de comunicação estratégica e de gerenciamento de crises têm remetido à sistematização de atividades
voltadas para as organizações que se encontram em situação de risco. Ações padronizadas e que se repetem como
receituários para casos de emergência se disseminam na bibliografia da área e em estudos acadêmicos como reflexo do cotidiano organizacional. Pensar no desenvolvimento das práticas de gerenciamento de risco exige que se apontem outros caminhos e que os gestores, guiados pelas relações públicas, vislumbrem horizontes mais seguros.

\section{DA CRISE AO CONFLITO}

A definição de crise passa pelo enquadramento da ação enquanto evento, submetendo-a a tipologias do tipo intencionais e não-intencionais, por exemplo. Decorre dessa submissão do olhar a falsa categorização do processo de crise, restringindo a ação estratégica da comunicação às etapas do antes, durante e após o evento. Compreender o processo de comunicação envolvido nos movimentos políticos e culturais provoca o enfrentamento de conflitos que surgem de qualquer natureza, em qualquer tempo e em qualquer ambiente organizacional.

Por isso, a observância nas redes de relações instituídas pelas instâncias participantes do processo em andamento é fundamental para a tomada de atitudes certeiras e que minimizem o impacto entre as partes envolvidas no conflito. 0 entendimento dos diferentes pontos de interesses presentes numa situação de crise é importante para superar os regramentos impostos pela visada funcionalista do processo.

A abordagem que persegue os estudiosos em gerenciamento de crise entende-a como "uma ruptura na normalidade da organização; uma ameaça real ao negócio, à reputação e ao futuro de uma corporação ou de um governo" (Forni, 2013, p. 8). 0 desafio que se lança é como compreender o processo de crise que se instala numa comunidade, que ameaça a vida em sociedade e desestabiliza as rotinas dos cidadãos. 0 estado de exceção que se instala em cidades que passam por grandes traumas como Nova York, nos Estados Unidos, nos atentados de 11 de setembro de 2001, como em Santiago do Chile, no terremoto de fevereiro de 2010, e como em Santa Maria, no Brasil, no incêndio da boate Kiss em 27 de janeiro de 2013, precisa ser entendido na complexidade do lugar da vigilância, que excede a compreensão de crise.

Por isso, a mudança do paradigma da crise deve passar, inicialmente, pelo entendimento da vigilância.

Gilles Deleuze introduziu a expressão 'sociedade de controle', na qual a vigilância cresce menos como uma árvore - relativamente rígida, num plano vertical, como o panóptico - e mais como ervas daninhas. Como observam Kevin Haggerty e Richard Ericson, a 'montagem da vigilância' capta fluxos do que se poderia chamar de dados corporais, transformando-os em 'duplicatas de dados' altamente móveis e fluidas. William Staples também observa que a vigilância atual ocorre em culturas 'caracterizadas pela fragmentação e pela incerteza, quando muitos dos significados, símbolos e instituições antes tidos como certos se dissolvem diante de nossos olhos'. Assim, o que é seguro, estruturado e estável se liquefaz (Bauman, 2013, p. 12).

As relações deflagradas pelas situações de crise ultrapassam a gerência administrativa do evento trágico em suas circunstâncias temporais e territoriais, isto porque o estado de crise ultrapassa esses limites e impossibilita um gerenciamento que atue unicamente no controle da base organizacional. Como explica Bauman no texto citado, há uma dissolução do sentimento de segurança que passa a exigir um lugar permanente de vigilância. Vigiar e ser vigiado deve ser o estado inicial das organizações para saber fazer durante eventos que provoquem o estado de crise, como os ocorridos em Santa Maria, Santiago e NovaYork. 
Para Mitroff (2001, p. 8), "muito antes de realmente ocorrer, praticamente todas as crises enviam repetidos 'sinais de alerta', anunciando a provável ocorrência da crise. (...) Em suma, elas [as organizações] precisam deixar de ser reativas para ser proativas continuamente". Estar em alerta significa estar pronto para ultrapassar, com medidas éticas e responsáveis, do estado de conflito para o lugar dos afetos. Este lugar exige que as organizações tenham ciência, antecipadamente, do seu papel social e da importância da construção e do cuidado dos vínculos entre os sujeitos envolvidos no processo comunicativo deflagrado.

A relação entre os vínculos instituídos e o cenário organizacional em vigilância é potencializada pelas esferas culturais - 0 espaço de empoderamento dos afetos. Para George Yúdice (2013, p. 497), "de maneira conexa, em nossa chamada sociedade pós-moderna está surgindo uma nova forma de trabalho cujo modelo são as práticas criativas e inovadoras dos artistas". A atividade cultural criativa permite que as organizações transformem o estado de conflito em fazer criativo por meio do engajamento na gestão cultural. Por isso a mudança do paradigma de crise para o entendimento do conflito deve ser inerente às organizações. 0 investimento nas indústrias criativas permite a ocupação de um novo posicionamento, "uma vez que a cultura é o que 'cria o espaço onde as pessoas se sentem seguras e em casa, onde elas se sentem como pertinentes e partícipes de um grupo', de acordo com essa perspectiva, ela é condição necessária para a formação da cidadania" (Yúdice, 2013, p. 45).

Em janeiro de 2013 a cidade de Santa Maria, na região sul do Brasil, teve deflagrada sua pior situação de crise. Narrado pelo discurso midiático como a "maior tragédia gaúcha", o fato ganhou visibilidade internacional e comoveu milhares de pessoas pelo impacto do incêndio que vitimou 242 jovens. 0 estado de comoção, de revolta, de desconsolo e até de curiosidade tomam os sujeitos que habitam a cidade ou que circulam temporariamente por ela. Essa situação, fomentada pelo enquadramento da mídia, pela lentidão do sistema judiciário e pela inoperância dos poderes governamentais e políticos condicionam um estado de conflito permanente na região.

Passados quase três anos, a situação ainda é geradora de conflitos. 0 estado de crise permanece e as reações relatadas pelos comentários ${ }^{1}$ dos leitores na página do Facebook do jornal de maior circulação na cidade em 27 de janeiro de 2015, mostram a urgência no desenvolvimento de ações que levem ao lugar dos afetos:

"Um dia a dor vai acalmar... mas cada um sabe quando é hora de parar de chorar. Não critiquemos pois quem ainda está como coração em frangalhos."

"Eh muito sofrimento! As pessoas q perderam seus familiares deveriam ocupar seus corações e mentes com atitudes positivas e acreditar q a JUSTIÇA vai ser feita!!! E não fiquem se martirizando se auto-fragelando!! Santa Maria sofreu muito com a tragédia mas parece q estao COMEMORANDO cada ano de maneira diferente. Vamos viver, vamos amar e fazer o que estes jovens gostariam de fazer se aqui estivesse e acreditar que a justiça vai ser feita seja ela qual for e como for mas nao podemos desistir!!"

0 papel dos afetos é o de deslocamento dos desejos inconscientes, discursivamente relatados nos posts dos leitores do jornal. A vontade real dos cidadãos que se expressam nas redes sociais e que tangencia um discurso padrão na cidade é a vontade de ter uma outra narrativa a partir do acontecimento negativo. Experimentar o outro passa a ser o agente motivador e impulsionador para a saída de situações de crise.

As técnicas de gerenciamento de crise, deflagradas por um evento de natureza não especificada, não atende situações como essa que assolou Santa Maria, no interior do estado gaúcho. A gestão de crise não se aplica à boate que se incendiou, porque reconstruir o espaço e a imagem da danceteria é inimaginável numa sociedade ética e saudável. Entretanto o "espírito de crise" tomou conta de todas as organizações - privadas e públicas - que desconhecem seu papel no gerenciamento dessa situação.

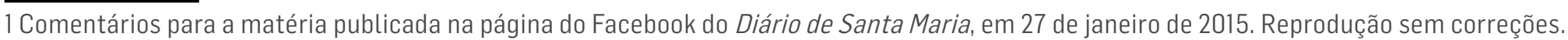


Casos assim é que permitem a ultrapassagem da crise para o conflito, passando pelo entendimento dos afetos. Há um estado de conflito permanente que atinge a cidade e todos os seus segmentos. Dessa forma, por meio da visada do conflito é possível entender a necessidade do equilíbrio de interesses mediante ações que busquem a troca de afetos. Em recente estudo sobre a apropriação do espaço dos tapumes que escondem a fachada da boate incendiada e que se transformou num lugar de construção de sentidos, Fausto Neto, Fabricio e Weschenfelder $(2014$, p. 2) defendem que há o entendimento de

uma espécie de interdição de natureza simbólica e da qual resulta a criação de um espaço onde são tecidas várias discursividades. A edificação abriga a presença de várias lógicas e suas operações, segundo um eixo convergente pelo qual se exteriorizam mensagens de celebração do luto. Possivelmente, uma das marcas simbólicas mais reveladoras deste processo de interdição/ apropriação, e que emana do poder deste coletivo (...).

As vozes que compõem as discursividades apontadas pelos autores precisam estar em permanente vigilância. Conhecendo o teor de suas falas, é possível sair do lugar de passividade e ir ao encontro de soluções criativas e que conduzam ao espaço dos afetos.

Em situações conflituosas nas quais há disputas de interesses de muitos sujeitos, o percurso que leva ao consenso passa pela ocupação do espaço público e a reconfiguração dos sentidos simbólicos acionados na ação criativa. Antigamente o espaço público era equivalente ao espaço de liberdade do cidadão, em oposição ao privado. Muniz Sodré (2002) explica que público é, primeiramente, a designação do controle ou do ordenamento estatal (direito e político) da vida social. Depois, é o espaço onde a sociedade torna visível tudo aquilo que tem em comum. 0 espaço público, então, é considerado o local pertencente ao poder público que, por meio do uso comum e da posse de todos, proporciona encontros e relações entre as pessoas.

\section{DO CONFLITO AO ESPAÇO PÚBLICO}

A criatividade é inerente ao ser humano, mas a criatividade só aflora se tiver um incentivo. É importante que existam espaços estimulantes nas cidades e que atraiam os sujeitos criativos e sirvam de inspiração para os mesmos. Por isso, 0 espaço público não pode ser pensado para um grupo de pessoas, mas deve ser desenvolvido para servir de inspiração para a criatividade. Esses espaços são por excelência lugares físicos e sociais onde as diferenças, as percepções, as identidades e os conflitos são exacerbados pelos diferentes grupos num cotidiano de práticas e usos diversos.

A ideia de que as cidades possuem uma esfera pública, pertencente e usada pela coletividade, e uma esfera privada, cuja posse e manutenção respondem aos interesses de um ou mais indivíduos específicos, é bastante antiga e foi durante a Antiguidade Clássica, com a urbanística grega, que essa ideia veio a definir-se totalmente. Para os gregos, a ágora era o espaço que, inserido na pólis, representava o espírito público desejado pela coletividade da população e onde se exercia a cidadania.

Segundo Gomes (2002, p. 162), para compreender a origem do espaço público, deve-se retornar à Grécia Antiga, onde, durante as reformas do tirano Clítenes, fundador da democracia grega, nasce o espaço público e também uma nova imagem do homem grego, agora cidadão pertencente a uma porção territorial determinada.

A definição de esfera pública também foi muito utilizada em meados do século XVI, com o capitalismo mercantil e a burguesia, sendo denominada esfera pública burguesa. Na época, a esfera pública, assim como a ágora, representava 0 lugar onde a atuação do estado era discutida e, até mesmo, criticada pela burguesia. A participação nessa esfera também era restrita a cidadãos do sexo masculino. 
$\mathrm{Na}$ idade moderna os espaços públicos continuavam a expressar a condição da população urbana, seus costumes e suas práticas socioespaciais. Buscando ilustrar a importância das praças como espaços públicos na idade moderna, Burker (1989, apud Coradini, 1995, p. 23), salienta que,

nos países mediterrâneos, o centro efetivo da cultura popular era a piazza. Havia apresentações de bonecos na praça do mercado de Sevilha no século XVII, enquanto em Madri podia-se assistir a peças, touradas, corridas e torneios na Plaza Mayor. (...) Em Veneza, era na Piazza San Marco que os principais charlatões montavam seus estrados, soltavam suas piadas e vendiam os seus remédios.

Verifica-se, nesse período, uma crescente valorização da praça como espaço de convívio social, no qual diversas formas de expressão cultural são divulgadas por múltiplos atores sociais, como "charlatões, malabaristas, saltimbancos, curandeiros e alguns artistas itinerantes que se deslocavam de um lugar para outro", conforme cita Burker (1989, apud CORADINI, 1995, p. 23). Desde então se percebe a presença de "animadores" em locais públicos, atraindo o povo para esses ambientes e estimulando-os a utilizar esses espaços para o desenvolvimento do lazer e da vida social.

Com o decorrer do tempo, já no período pré-industrial, o espaço urbano passa a ser planejado e as praças são totalmente remodeladas, assumindo assim novas funções, diferentes das praças que, até então, valorizavam o convívio social. Sennett (1988, p. 75) diz que

as grandes 'places' urbanas não eram feitas para concentrarem todo o tipo de atividade das ruas circundantes: a rua não deveria ser pórtico para a vida da praça (...). A praça deveria ser um monumento a si mesma, com atividades restritas acontecendo em seu meio, atividades constituídas como de passagem e de transporte. Acima de tudo, essas praças não foram concebidas tendo em mente a multidão lenta que congrega.

As praças de usos múltiplos, tomadas por atividades culturais diversas, dão lugar a elas mesmas, ou seja, já não são mais as atividades e as pessoas que dão vida ao espaço público da praça, mas é ela a própria atração. Para Ariés (apud Coradini, 1995, p. 25), "o espaço público não tem outra função a não ser a de permitir um deslocamento físico entra a casa, a loja e 0 trabalho". Com isso, as atividades sociais passaram a ser desenvolvidas em locais específicos como cafés, parques e teatros.

Conforme destaca Serpa (2007, p. 16) ao abordar o espaço público não se deve pensar apenas no espaço físico, mas, sobretudo, deve-se considerar que ele também possui um "caráter simbólico de apropriação social dos espaços públicos urbanos como tendo implicações que ultrapassam o design físico de ruas, praças, parques, largos, shopping centers e prédios públicos". Deve-se então considerar o espaço público como o lugar onde os grupos sociais expressam suas múltiplas formas e maneiras de apropriação, oferecendo ao espaço urbano uma identidade própria.

O espaço público é também, segundo Hannah Arendt (1972) o espaço da sociedade, o espaço político, sendo, necessariamente, um espaço simbólico, pois eles se opõem e respondem a discursos dos agentes políticos, sociais, religiosos, culturais, intelectuais que constituem uma sociedade. Nesse sentido, o espaço público tira a multidão da passividade de um cotidiano que transformou toda discussão social em espetáculo e a torna capaz de agir dentro do espaço público.

O espaço público é considerado um local em que ocorrem trocas de ideias e interação entre vários indivíduos, onde todos têm o mesmo direito de voz, ou seja, de falar e ser ouvido. Ele também pode ser entendido como um local de negociação de opiniões e interesses, onde o poder está sendo sempre disputado, isto é, os indivíduos ali presentes têm sempre a intenção de fazer valer a sua ideia para que possam dominar a situação. Isso thes proporciona uma posição na sociedade e, consequentemente, o bem-estar social. Por isso, esse espaço acaba se tornando um lugar de conflito, onde diversos 
indivíduos, cada um com a sua ideia, busca tomar o poder da situação, procura ter mais visibilidade que os demais. Resende (2005, p. 129) diz que "o espaço público contemporâneo, assim, significa o modo como se negociam saberes e poderes, ou, ainda, o modo como se articulam forças e interesses em um mundo regido pelos meios de comunicação; ele é, por tudo isso, o espaço cuja nova norma é o conflito".

Nesse sentido, Gomes (2002, p. 162) argumenta que o espaço público constitui o local responsável pela reprodução da vida coletiva, sendo assim "o lugar, praça, rua, shopping, praia, qualquer tipo de espaço que não possua obstáculo à possibilidade de acesso de qualquer tipo de pessoa". Ainda, pode-se dizer que o espaço público é o espaço onde se desenvolvem a vida urbana, suas relações sociais, políticas, econômicas, culturais, enfim, "lugar de conflitos, de problematização da vida social, mas, principalmente, é o terreno onde esses problemas são assinalados e significados".

Para o autor, o espaço urbano contemporâneo expressa essa multiplicidade vivida pela sociedade, sendo esta formada por várias diferenciações internas observáveis, como "a etnia, sexo, idade, função ou qualquer outro elemento" (Gomes, 2002, p. 66). Esse particularismo que cada grupo social expressa em determinado espaço, dá origem a um lugar próprio e único, carregado de identidade social.

Diante dessas inúmeras formas, funções e práticas sociais desenvolvidas no espaço das praças em diferentes épocas, pode-se afirmar que esse espaço foi de extrema importância para a organização espacial das cidades criativas e para 0 desenvolvimento da vida social.

Percebe-se então que os atuais projetos urbanos contemporâneos são realizados no mundo inteiro segundo uma mesma estratégia homogeneizadora, espetacular e consensual, buscando transformar os espaços públicos em cenários, ou seja, em uma imagem publicitária. Em decorrência disso, as imagens de distintas cidades se parecem cada vez mais entre si.

Atualmente não existe lugar para qualquer tipo de espaço contra-hegemônico, o que resulta no empobrecimento da própria experiência urbana, em particular da experiência sensível e corporal das cidades. As novas praças, ditas "praças", dos shoppings, além de privadas, são extremamente controladas e policiadas, configurando espaços pacificados, ou seja, espaços onde os conflitos são eliminados. Trata-se de uma ideia totalmente contrária à de Chantal Mouffe (2007), o qual diz que o espaço público é um eterno campo de batalha onde se enfrentam diferentes interesses, ao contrário dessas imagens de espaços públicos homogeneizados.

Então, o aspecto crucial dessa configuração contemporânea das cidades é o do empobrecimento da experiência urbana dos seus habitantes, cujo espaço de participação civil, de produção criativa e vivência afetiva está cada vez mais restrito quanto às suas oportunidades de ocorrência.

Em maio de 2015 foi publicado no jornal Diário de Santa Maria, e repercutido nas redes sociais, a proposta para a construção de um centro para a juventude no terreno ocupado pelo que restou da boate Kiss. A lógica, amplificada pela visada midiática, é a da transformação do local em espaço de convívio público. Entretanto, ela não segue um percurso de vigilância das vozes e amplificação das falas por meio das esferas culturais, mas parte do embate causado pela apropriação e desapropriação do território material e simbólico: "Ministério Público, prefeitura, entidades e familiares apoiam propostas. Pais divergem quanto à forma de aquisição do terreno", estampava a manchete publicada no jornal. 


\section{ANO 12 • NÚMERO 23 • 2오. SEM. 2015 • ORGANICOM \\ A OCUPAÇÃO DO ESPAÇO PÚBLICO PARA A RESOLUÇÃO DE CONFLITOS: CONSTRUINDO CIDADES CRIATIVAS}

A tomada do espaço e a sua constituição como lugar público ocupa, como é possível verificar, não o embate na praça e que poderia levar à resolução do conflito, mas a voz mediadora da mídia que provoca instabilidades e instiga a construção do lugar comum, sem a efervescência criativa provocadas por outros modelos dialógicos. Segundo o recorte da imprensa, há uma urgência na tomada territorial: "Se não houver apoio da AVTSM", o prédio vai continuar como está, pelo menos enquanto estiver sob os cuidados da Justiça. Se não houver a desapropriação ou se o imóvel não for comprado para a construção de um memorial, ao final do processo, a empresa pode fazer com ele o que quiser". Esse tipo de argumento que agenda o fazer público, político e organizacional, desfaz as bases para a construção de cidades criativas capazes de transformar a estrutura socioeconômica e cultural. A urgência para apagar o conflito apagará as potencialidades criativas da cidade e com isso a não-transformação do espaço em ambiente público que respeita a singularidade da comunidade que dele desfruta.

Figuras 1: Imagens do local da tragédia: impasse na ocupação criativa do lugar impossibilita a saída da situação de crise ${ }^{3}$.
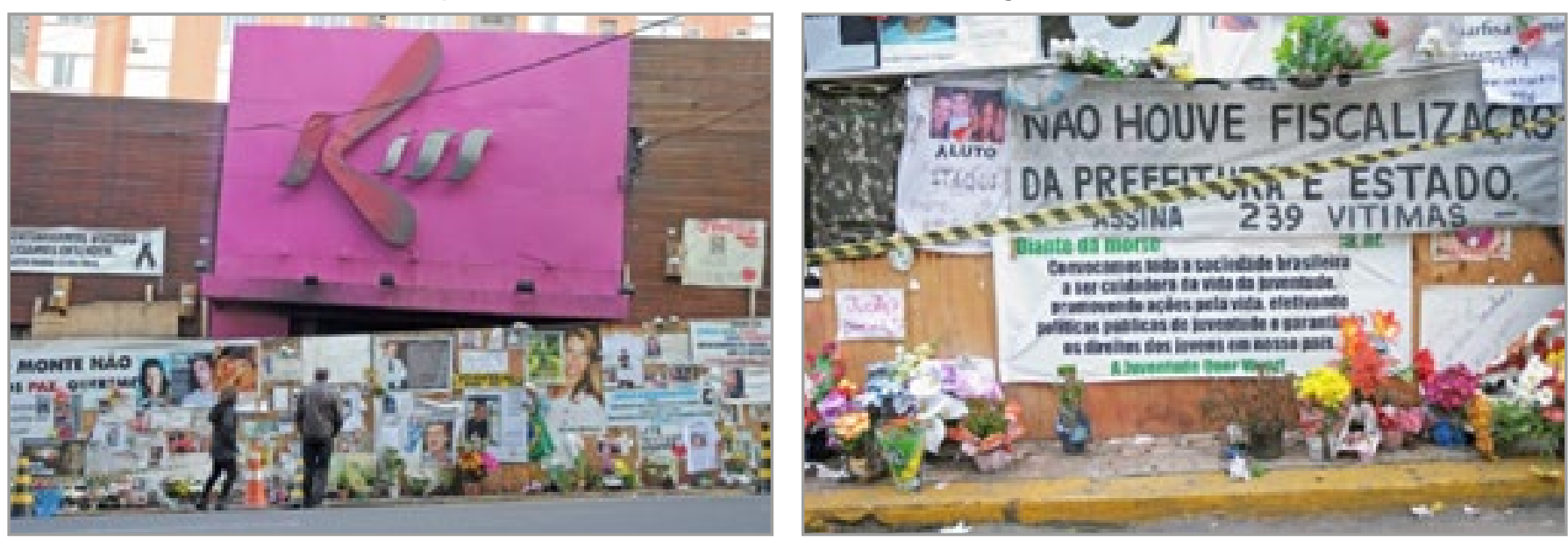

A tomada do lugar público deve impulsionar a resolução dos conflitos, porque permite a completude simbólica do cidadão que vê seu espaço respeitado pelas instâncias políticas e econômicas da cidade. Os casos relatados como sucesso na modelagem de cidades criativas partiram da resolução de conflitos que tomaram as cidades por longos períodos de tempo.

A potencialização criativa e a formação de redes de conhecimento possibilitam a saída do conflito por meio de uma visada colaborativa e com a participação ativa das organizações, que obtêm ganhos de imagem apoiando iniciativas desse porte. Bilbao, Barcelona e Medellín, para citar os exemplos mais emblemáticos, são cidades que apostaram nas indústrias criativas para a superação dos conflitos por meio do remodelamento do espaço público. Essas ações são impulsionadas pela participação das organizações privadas, governamentais e não-governamentais que atuam sinergicamente para a saída do conflito.

\section{DO ESPAÇO PÚBLICO ÀS CIDADES CRIATIVAS}

A economia criativa é uma forma de gerar desenvolvimento econômico por meio da propriedade intelectual do ser criativo. Essa economia, como qualquer outra, precisa de um mercado, e o principal mercado da economia criativa são os espaços públicos. Segundo Reis (2007, p. 311),

a economia criativa envolve governo, setor privado e sociedade civil em um programa de desenvolvimento sustentável que utiliza a criatividade para se inspirar nos valores culturais intangíveis de um povo, gerar localmente e distribuir globalmente bens e serviços de valor simultaneamente simbólico e econômico.

2 Associação dos Familiares de Vítimas e Sobreviventes da Tragédia de Santa Maria.

3 Créditos das imagens: Laura Fabrício. Disponível em: <htpp://www.ciseco.org.br/index.php/noticias/53-boate-kiss>. Acesso em: 15 maio 2015. 
0 desenvolvimento a partir dos princípios da economia criativa permite que as cidades se desenvolvam potencializando suas experiências identitárias e contextuais com o auxílio na iniciativa pública e privada.

As cidades criativas são aquelas que investem no vínculo com os seus atores sociais, e a primeira ação que lhes ocorre é a qualidade dos espaços públicos. Locais como parques municipais, praças e praias urbanas estão despertando um forte e amplo interesse pela arquitetura. Têm-se como exemplos parques em Paris - Parc de la Villette e Parc Bercy - que foram construídos em espaços industriais em desuso. As cidades criativas buscam locais que exalam uma vida diária, ao mesmo tempo em que são memoráveis por eventos ocasionais, considerados únicos.

Os meios de comunicação também são significativos para o entendimento da construção criativa das cidades, considerando os espaços públicos como setores da sociedade onde se travam disputas ideológicas. Uma das características modernas do espaço público mediatizado, fruto do vertiginoso crescimento dos meios de comunicação de massa, é a sua privatização. Segundo Marilena Chauí (1992, p. 384), "privatização significa desinstitucionalização do espaço público e corresponde ao fortalecimento dos centros privados onde se dá a decisão econômica e ao enfraquecimento dos estados nacionais".

Sodré (2002, p. 40) ressalta que "o espaço público da contemporaneidade é cada vez mais construído pelas dimensões variadas do entretenimento ou da estética". 0 autor ainda considera o espaço público profundamente afetado pela esfera do espetáculo, em que "a vida comum torna-se médium publicitário e transforma a cidadania política em performance tecnonarcísica". 0 resultado é a prevalência da mídia na cena pública de hoje.

Dentro dessa lógica espetacular de criação de imagens e construção de consensos, os espaços públicos contemporâneos são vistos como estratégicos para a construção e a promoção da imagem de marcas, ou seja, são pensados enquanto peças publicitárias, para consumo imediato. Marilena Chauí (1992, p. 385) diz que "o fenômeno mais importante é a passagem do espaço público à condição de marketing, merchandising e midiatização e a do espaço privado à condição de privacidade intimista, mas, sobretudo, à perda de fronteira entre ambos". Ou seja, o fenômeno mais importante na contemporaneidade é a perda de fronteiras entre espaço público e privado, abrindo possibilidades de interação e diálogo.

Associada à visada do espaço público como propulsor da resolução dos conflitos e na contramão do embate travado pela Associação dos Familiares de Vítimas e Sobreviventes da Tragédia de Santa Maria e pela prefeitura da cidade, um grupo de moradores, atentos ao seu espaço privado e desejosos da retomada da criatividade em suas vidas, abriu as portas das suas casas, compartilhou suas calçadas e levou para as ruas de um bairro antigo e tombado pelo patrimônio histórico e cultural de Santa Maria a retomada dos afetos.

Figuras 2: Brique da Vila Belga ${ }^{4}$

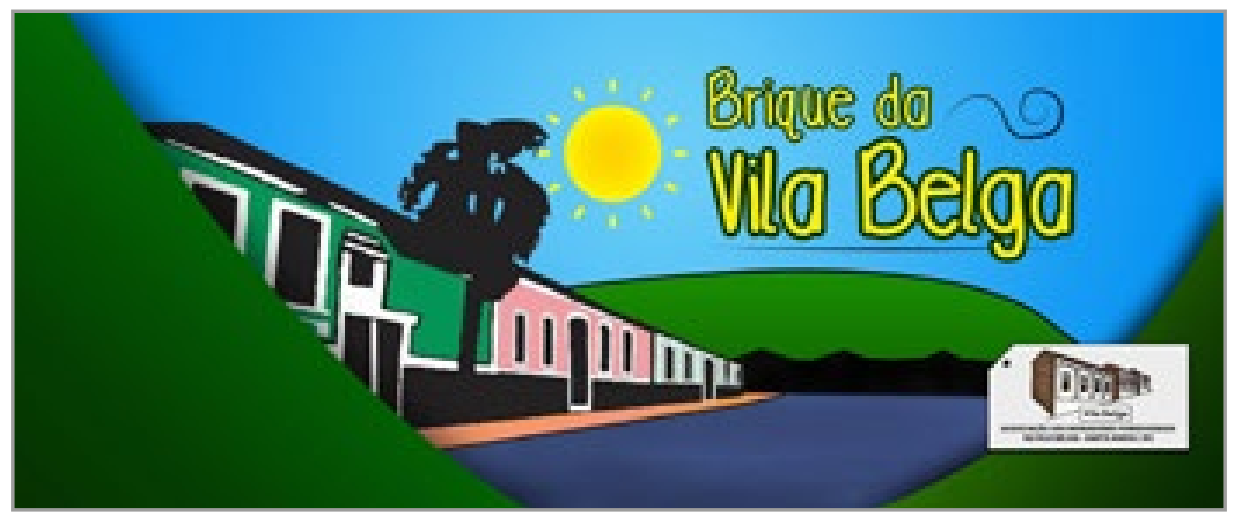

4 Imagens disponíveis na fanpage do evento "Brique da Vila Belga". 


\section{ANO 12 • NÚMERO 23 • 2은. 2015 • ORGANICOM \\ A OCUPAÇÃO DO ESPAÇO PÚBLICO PARA A RESOLUÇÃO DE CONFLITOS: CONSTRUINDO CIDADES CRIATIVAS}
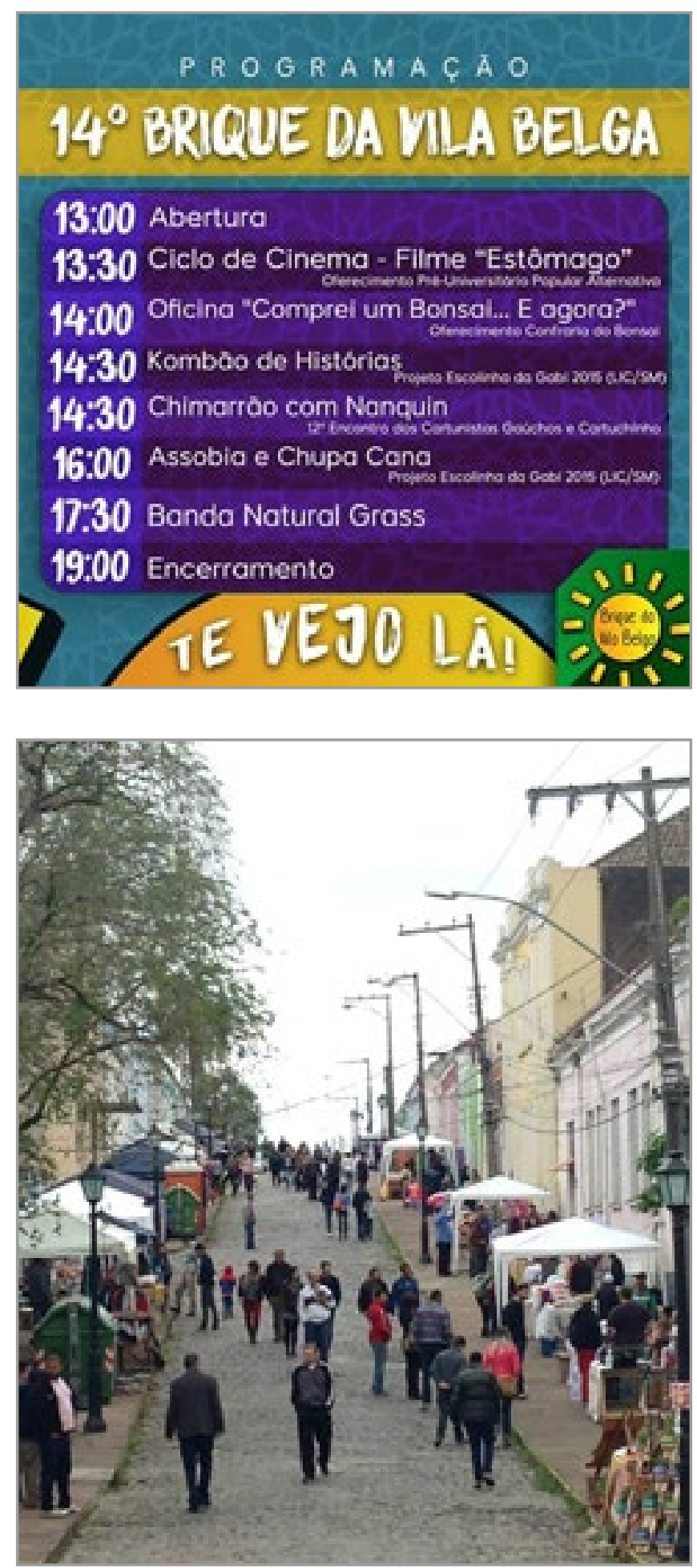

Em sete meses de atividades, a ação reúne milhares de pessoas que buscam histórias, gastronomia, lazer e interação nas ruas da Vila Belga e nas edificações projetadas em 1903 para abrigar as famílias de trabalhadores de uma companhia ferroviária belga. 0 Brique da Vila Belga é um lugar que emerge do contexto social, cultural e econômico da cidade de Santa Maria e proporciona ao cidadão um sentimento de pertencimento e de identidade territorial que todo espaço público deve oferecer em cidades criativas.

Por isso entende-se que a economia criativa é a nova oportunidade para as organizações, que se situam em cidades que passam por situações de conflito, construírem um diferencial no mercado competitivo e interagirem com os sujeitos, com seus públicos, com os cidadãos.

Portanto, a indústria criativa, que surgiu da necessidade entre os governantes que buscavam alternativas para gerar crescimento na economia, é determinante na resolução de conflitos, especialmente em situações mediadas pelo aparato midiático que potencializa o conflito. A economia criativa, decorrente do modelo produtivo da indústria, não possui um 
padrão a ser seguido e oferece a oportunidade de cada cidade encontrar um modelo próprio, possibilitando a transformação de seus potenciais criativos como a base de uma estratégia de desenvolvimento econômico.

Por meio da experiência do Brique da Vila Belga, percebe-se que as cidades criativas contribuem para o desenvolvimento econômico da região. Em cidades como Santa Maria, os espaços públicos tornam-se polos de inspiração para a criatividade, oferecendo um ambiente favorável e inspirador à produção, além de obter sua função base de convivência social. Mas, para que as cidades ajudem no desenvolvimento econômico, elas devem atrair e reter as pessoas criativas, oferecendo condições criativas que as façam se inserir nesses locais. Sendo assim, o espaço público é primordial para dar sustentação à cidade criativa, o que significa que é necessária uma atenção redobrada para a recriação de espaços públicos.

\section{CONSIDERAÇÕES FINAIS}

Diante do exposto, é possível encaminhar a reflexão para um caminho que vislumbra o investimento em cidades criativas como alternativa para situações de conflito. Para que os afetos circulem entre os atores sociais que fomentam a cena urbana e pública, e que experimentam o conflito deflagrado por situações extremas de tragédias e acidentes de grande apelo e impacto emocionais, é necessário que as instâncias de resistência atuem com inteligência criativa.

A retomada do lugar público e o não-abandono da cidade traumatizada pela violência vivida deve ser o lugar de partida para o desenvolvimento econômico impulsionado pelo espaço criativo da cultura. A dimensão social da cultura passa a ser campo para a transformação do cidadão como agente do espaço público.

A imobilidade do poder governamental frente a alternativas criativas que retomam a cena cultural da cidade de Santa Maria endossa a sua não-ação para o lugar do conflito. O Brique da Vila Belga é resultado de uma experiência ligada ao cotidiano de moradores que estendem suas redes de memória e as transformam em práticas de saberes compartilhados criativamente, numa atitude que estabelece novas relações sociais. Resta saber, entretanto, quando o lugar da governança será acionado para consolidar as esferas mobilizadas pelos indivíduos. A participação desse setor é fundamental para a desarticulação do estado de conflito e para a confirmação das cidades criativas.

É notório como a sociedade contemporânea é atravessada por conflitos que a impactam com graus diferentes e que são travados especialmente na tomada do espaço público. Nesse cenário onde as conexões de afetos contribuem para 0 desenvolvimento de uma cidade criativa é que se firmam os movimentos que direcionam para um outro entendimento acerca da crise e de seus reflexos nos sujeitos sociais, nas instâncias simbólicas e nas esferas de poder. As cidades criativas ainda têm muito a ensinar e a contribuir com os estados de crise tratados de maneira tão pouco criativas e sem a visada para além do conflito.

\section{REFERÊNCIAS}

ARENDT, Hanna. Entre o passado e o futuro. São Paulo: Perspectiva,1972.

BAUMAN, Zygmunt. Vigilância líquida. Rio de Janeiro: Zahar, 2013. 
CHAUÍ, Marilena. Público, privado, despotismo. In: NOVAES, Adauto (Org.). Ética. São Paulo: Companhia das Letras, 1992.

CORADINI, Lisabete. Praça XV: espaços e sociabilidade. Florianópolis, SC: Fundação Franklin Cascaes; Letras Contemporâneas, 1995.

DELGADO, Manuel. La ciudad mentirosa: fraude y miseria del "modelo Barcelona". Madrid: Catarata, 2007.

FAUSTO NETO, Antonio; FABRICIO, Laura; WESCHENFELDER, Aline. Da boate ao "memorial-tapume": quando a recepção enuncia suas formas de 'trabalho de luto'. In: ENCONTRO ANUAL ASSOCIAÇÃO NACIONAL DOS PROGRAMAS DE PÓSGRADUAÇÃO EM COMUNICAÇÃO, XXIII, Belém (PA), 2014. Trabalho apresentado no GT "Recepção: processos de interpretação, uso e consumo midiático". Disponível em: <http://compos.org.br/encontro2014/anais/Docs/GT15_RECEPCAO_PROCESSOS_ DE_INTERPRETACAO_USO_E_CONSUMO_MIDIATICOS/textocompos2014_lutonotapume_2270.pdf>. Acesso em: 10 maio 2015.

FORNI, João José. Gestão de crises e comunicação: o que gestores e profissionais de comunicação precisam saber para enfrentar crises corporativas. São Paulo: Atlas, 2013.

GOMES, Paulo César da Costa. A condição urbana: ensaio da geopolítica da cidade. Rio de Janeiro: Bertrand, 2002.

MITROFF, lan I. Managing crises before they happen: what every executive and manager needs to know about crises management. New York: Amacom, 2001.

MOUFFE, Chantal. Politicas artísticas y democracia agonística. Barcelona: Bellaterra (Cerdanyola del Vallès), 2007.

REIS, Ana Carla Fonseca. Economia da cultura e desenvolvimento sustentável: o caleidoscópio da cultura. Barueri, SP: Manole, 2007.

RESENDE, Fernando. A comunicação social e o espaço público contemporâneo. Alceu - Revista do Departamento de Comunicação Social, PUC-Rio, Rio de Janeiro, v. 5, n. 10, p. 129-145, 2005.

SENNETT, Richard. O declínio do homem público: as tiranias da intimidade. São Paulo: Companhia das Letras, 1988.

SERPA, Ângelo. O espaço público na cidade contemporânea. São Paulo: Contexto, 2007.

SODRÉ, Muniz. Antropológica do espelho. Uma teoria da comunicação linear e em rede. Petrópolis, RJ: Vozes, 2002.

YÚDICE, George. A conveniência da cultura: usos da cultura na era global. Belo Horizonte: Editora da UFMG, 2013.

Artigo recebido em 17.5.2015 e aprovado em 23.11.2015. 